\title{
A Critical look at Organic Photovoltaic Fabrication Methodology: Defining performance enhancement parameters relative to active area
}

\section{L.J. Rozanski, Chris T.G. Smith, Keyur K. Gandhi, Michail J. Beliatis, G. Dinesha M.R. Dabera, K.D.G. Imalka Jayawardena, A.A. Damitha T. Adikaari ${ }^{1}$, Michael J. Kearney and S. Ravi P. Silva*}

Advanced Technology Institute, University of Surrey, Guildford, Surrey, GU2 7XH, United Kingdom

* Corresponding Author's Email: s.silva@surrey.ac.uk, Telephone: +44 (0)1483689404

${ }^{1}$ Author's present address: Department of Energy \& Climate Change, 3 Whitehall Place, London, SW1A 2AW, United Kingdom

\section{KEYWORDS: Organic Photovoltaics, Organic Solar Cells, Reproducibility, Masking, Efficiency, Area}

Abstract: With the ever-increasing focus on obtaining higher device power conversion efficiencies (PCEs) for organic photovoltaics (OPV), there is a need to ensure samples are measured accurately. Reproducible results are required to compare data across different research institutions and countries and translate these improvements to real-world production. In order to report accurate results, and additionally find the best-practice methodology for obtaining and reporting these, we show that careful analysis of large data sets can identify the best fabrication methodology. Furthermore, we demonstrate which OPV outputs are most affected with different fabrication or measurement methods. We also identify that masking effects can result in artificially-boosted PCEs by increasing fill factor and current densities, making a minimal mask size a requirement for accurate results. We illustrate the necessity for reporting the best PCE along with the average value in order to implement changes in real-world production.

\section{Introduction}

As organic photovoltaics (OPV) have been moving towards record power conversion efficiencies (PCEs), translating these novel technologies to real-world products is becoming not just a reality, but a critical component for renewable energy [1]. Currently, a well-studied polymer has gained considerable interest, poly[[9-(1-octylnonyl)-9H-carbazole-2,7-diyl]-2,5-thiophenediyl-2,1,3benzothiadiazole-4,7-diyl-2,5-thiophenediyl] (PCDTBT), for achieving up to 7.5\% PCE when combined with [6,6]-phenyl-C70-butyric acid methyl ester $\left(\mathrm{PC}_{70} \mathrm{BM}\right)$ [2]. Recent literature has focused not only on increasing PCEs, but also providing proof of concept with larger-area modules 
[3-5]. It has been difficult to replicate the high efficiencies seen in the small, research laboratoryscale OPV cells when scaling up to large areas. This is due to a host of factors, but has been primarily related to the high sheet resistance of the transparent electrode at larger areas $[6,7]$. Considering the variety of new materials being produced and the potential to modify both active layers and interfacial layers, determining which is the optimal device 'recipe' requires a full analysis of thoroughly tested (and reproducible) results. Producing a reliable and well-understood reference device is a necessity when examining new materials. It is also essential to determine if new materials or changes to a device structure produce consistent and effective results. Reproducibility is desirable for many groups, ours included, as our history of working with novel inorganic nanomaterials $[8,9,10]$ as part of OPV have resulted in enhanced outputs [11]. As we are keen to ensure these results can be translated to larger area devices, (essential for shifting new technology into products), fabricated device reproducibility will also help streamline new material trials. Prior to scaling up to larger areas, accurate measurements are necessary, preferably on a minimum active area under controlled conditions. Examining the reproducibility of results across a large number of different device batches to determine where errors can be eliminated is also vital. The importance of these twin drivers becomes clear when examining the recent OPV meta-analysis provided by Jørgenson et al., where reported PCEs remained consistent across larger areas $\left(>1 \mathrm{~cm}^{2}\right)$ [12]. However, they noted significant variation occurring with single layer OPV below $0.5 \mathrm{~cm}^{2}$ active areas. Additionally, while this paper focuses on a simple donor-acceptor OPV device structures, variation across devices will increase considerably when using additives [13]. Large-scale analyses such as presented here can also help isolate the most promising additives.

As has been demonstrated by multiple research groups [14-18], a set standard of measurement conditions needs to be implemented to ensure the most accurate results are reported. Ultimately, the standard for reporting high PCEs requires certification by internationally-recognized agencies such as NREL or Fraunhofer ISE. While this requirement is accepted as standard, it isn't a 
feasible option for most university laboratories as a means of confirming their day-to-day results while trying to improve known systems and publish results. Furthermore, an in-depth analysis of data produced over the course of a project can identify problems in the manufacturing process or find errors in measurement/reporting accuracy. Conversely, a large-scale analysis of multiple samples can isolate the most promising methodology from the natural variation occurring across researchers following a standard recipe and 'tweaking' it to optimize results, which would give rise to local minima. Additionally, the parameters which do not affect the final results (such as small variations in film thickness from different spin speeds) can also be identified as areas where further research is unnecessary. Herein we show the importance of such an analysis, which can then be applied to larger area OPV, which require higher-throughput fabrication methods such as printing.

There should also be consideration of the OPV active area under examination, as larger areas are needed for translation to the marketplace. Numerous groups have reported decreasing solar cell efficiencies with increasing active area, which we believe is primarily the result of increased indium tin oxide (ITO) electrode sheet resistance [19-23]. Even with the awareness that small OPV active areas can artificially boost PCE through excess current collection $[24,25]$, some recent papers fail to state their active area dimensions when reporting high PCEs. Fewer report the reproducibility and/or variation, although the trend is now shifting towards presenting data in this manner [26-31]. With the increasing demand for good results, focus has shifted to generating ever higher PCE numbers, or 'hero devices' which are hard to reproduce in competitor laboratories [12]. As a result, it is impossible to ascertain if a reported improvement occurs for one out of ten devices or one out of a thousand, knowledge vital for real-world production. Moreover, understanding which methodology produces reproducible results for new devices and materials, as well as ensuring these improvements translate to larger modules becomes crucial. This is why a shift towards larger OPV active areas, along with sharing details across research institutions [32] will move research towards more reliable, largely consistent results analyzed using a fixed methodology. 
We have undertaken analysis of multiple reference OPV samples, with slight variations in their recipe, across three years and numerous researchers to examine reproducibility and ensure we are reporting the best standard results. Initially this paper focuses on the effects of masking area relative to the full device area, and then moves onto analyzing results to determine which fabrication methods produce reliable, enhanced results. The fabrication recipe analysis was performed for: annealing temperature variation for Pedot-Pss, thickness changes for the different layers, solvent ratio used for the active layer, and masking area effects. Combinations of the above were examined in a complex matrix and analyzed against the history of process steps. For this paper, 133 single active area substrate devices were measured, with masking areas varied from $0.032 \mathrm{~cm}^{2}-0.64 \mathrm{~cm}^{2}$. This was done so that the best fabrication parameters can be then be scaled towards a full $1 \mathrm{~cm}^{2}$ active area, providing accurate measurements for industry standards.

\section{Experimental}

\subsection{OPV device structure and materials}

OPV devices were fabricated on $15 \mathrm{ohm} / \mathrm{sq}$. patterned ITO on glass substrates $(0.7 \mathrm{~mm} \times 15$ $\mathrm{mm} \times 15 \mathrm{~mm}$ ), purchased from Luminescence Technology Corp. with the ITO patterned in a centered $9 \mathrm{~mm} \times 15 \mathrm{~mm}$ strip, which was subject to a series of sonications in acetone and isopropanol, followed by an oxygen plasma treatment $(5 \mathrm{~min}, 100 \mathrm{~W}, 20 \mathrm{sscm} \mathrm{O}$, Emitect $\mathrm{K} 1050 \mathrm{X}$ plasma cleaner) prior to film deposition. The vertical layer configuration was: ITO/ PEDOT-PSS/ PCDTBT:PC $70 \mathrm{BM} / \mathrm{BCP} /$ Aluminum. Poly[3,4-ethylenedioxythiophene] poly[styrenesulfonate], (PEDOT-PSS, Clevios P VP AI 4083, purchased from Heraeus) was filtered $(0.45 \mu \mathrm{m})$, and the 40 $\mathrm{nm}$ thick film was annealed for 10 minutes between $160-200^{\circ} \mathrm{C}$. Poly[[9-(1-octylnonyl)-9Hcarbazole-2,7-diyl]-2,5-thiophenediyl-2,1,3-benzothiadiazole-4,7-diyl-2,5-thiophenediyl] (PCDTBT) was purchased from Solaris Chem Inc., and [6,6]-Phenyl C70 butyric acid methyl ester $\left(\mathrm{PC}_{70} \mathrm{BM}\right)$ was purchased from Solenne BV, both used without modification. 2,9-dimethyl-4,7-diphenyl-1,10phenanthroline (BCP or bathocuproine) from Luminescence Technology Corporation was 
evaporated through a shadow mask (4-16 nm thickness), followed by $75 \mathrm{~nm}$ of aluminium to complete the reference device. PCDTBT was used in a $7 \mathrm{mg} / \mathrm{mL}$ concentration to the $\mathrm{PC}_{70} \mathrm{BM}$ with varying solvent ratios of dichlorobenzene to chlorobenzene (from 1:0 to 3:1). All fabrication steps after PEDOT-PSS application were performed in a glovebox.

\subsection{Measurement and masking}

A precision calliper was used to measure the openings of completely opaque metal masks with the following areas: $0.032 \mathrm{~cm}^{2}, 0.123 \mathrm{~cm}^{2}, 0.283 \mathrm{~cm}^{2}, 0.385 \mathrm{~cm}^{2}$, and $0.64 \mathrm{~cm}^{2}$. Devices were measured in air, without encapsulation, using a four-point probe configuration, with the aluminium electrode and ITO electrode overlap of $0.90 \mathrm{~cm}^{2}$ centered on the $15 \mathrm{~mm} \times 15 \mathrm{~mm}$ square substrate to minimize excess charge collection [24],[18]. The holder is designed such that no light can penetrate around the edges of the mask or substrate once both are in place, and designed so that the device is at the same height as the reference silicon cell. The calibrated silicon reference cell (ReRa Systems), was $20 \mathrm{~mm}$ $\mathrm{x} 18 \mathrm{~mm}$ in area, and careful placement (within the marked areas) of the device holder was used to ensure reproducible measurements. An Abet Technologies 10500 solar simulator (class AAB) at AM 1.5G, 1-Sun was utilized for J-V measurements, while a Bentham Instruments PVE 300 with 1-Sun white light bias was used for external quantum efficiency (EQE) measurements.

\section{Results and Discussion}

\subsection{Masking effects}

We analysed a series of OPV devices with different masked areas to determine the effects of masking on device outputs, with Figure 1A showing the vertical device structure, and Figure 1B showing the energy levels for the materials used. In Figure 1C, we demonstrate a trend for OPV outputs relative to mask area. Here, a larger active area $\left(0.90 \mathrm{~cm}^{2}\right)$ is measured with a series of masks with decreasing area $\left(0.64 \mathrm{~cm}^{2}, 0.385 \mathrm{~cm}^{2}, 0.283 \mathrm{~cm}^{2}, 0.123 \mathrm{~cm}^{2}, 0.032 \mathrm{~cm}^{2}\right)$. For this device, as the illuminated mask area decreases relative to the full electrode area, there is a trend of slightly 
increasing $\mathrm{J}_{\mathrm{sc}}$, from $11.21 \mathrm{~mA} / \mathrm{cm}^{2}\left(0.64 \mathrm{~cm}^{2}\right.$ mask $)$, up to $12.59 \mathrm{~mA} / \mathrm{cm}^{2}\left(0.032 \mathrm{~cm}^{2}\right.$ mask $)$. The $\mathrm{J}-\mathrm{V}$ curve outputs for each area are shown in Supplementary Table 1. Across multiple samples, this trend of increasing $\mathrm{J}_{\mathrm{sc}}$ with decreasing mask area holds steady, which has been explained as increased light scattering effects or film inhomogeneity within the mask [14]. More importantly, there was a steady improvement in fill factor (FF) with smaller mask areas, artificially 'boosting' the resultant PCE through the combined effect of enhanced $\mathrm{J}_{\mathrm{sc}}$ and FF. This is offset slightly by a decrease in open circuit voltage $\left(\mathrm{V}_{\mathrm{oc}}\right)$, explained as viewing the shaded region as a dark diode in parallel with the illuminated diode within the center of the mask [36]. Although the authors in [36] did not see an increase in Jsc, we believe the Jsc increase in our data is the result of underestimating the actual illuminated area through light scattering effects [14], which is being addressed through larger apertures and thinner masks.

The enhanced $\mathrm{J}_{\mathrm{sc}}$ and FF contribute to the improved PCEs seen for the smaller masked active areas, an artefact we wish to remove from reported results. Thus we have analyzed samples to determine where the greatest contribution to this enhanced PCE occurs. The increased FF in part results from the decreased $\mathrm{V}_{\mathrm{oc}}$ as noted in [36], where the dark diode's (shaded portion) current offsets the lighted diode's (within the mask center) current. The resultant data also appears to mimic the 'low light effect', where photocurrent begins to show a linearly-increasing current respective to decreasing light intensity (generally well below 1 sun intensity) [37-39]. Interestingly, the median current values relative to mask area across all samples follow this linear response, shown clearly when plotted as a percentage of area illuminated within the masks relative to the full device area (Figure 2, black spheres), giving the appearance that the entire cell (averaged together) is seeing 'less than one sun'. As FF depends on the shunt and series resistances within the device, we have examined these relative to mask area to find which provides the largest enhancement on FF. Shunt resistances in particular have been shown to have a strong dependence on light intensity, especially 
under low light conditions. Series resistance (especially of the high-resistance ITO electrode), can also contribute considerably to FF.

In Figure 3A, a plot of raw shunt resistances $\left(\mathrm{R}_{\mathrm{sh}}\right)$ calculated using a model (IVFIT [41]), against mask area shows a substantial increase in the median values (red spheres) of shunt resistance with decreasing illumination area. To check the accuracy of the $\mathrm{R}_{\text {sh }}$ calculations from the IVFIT, a series of J-V curves were measured at higher reverse bias $(-0.5 \mathrm{~V})$ compared to the norm $(-0.3 \mathrm{~V}$ or $0.1 \mathrm{~V})$. Shifting the starting voltage between $-0.5 \mathrm{~V}$ and $-0.1 \mathrm{~V}$ resulted in some $\mathrm{R}_{\mathrm{sh}}$ variation, but not enough to affect the final OPV outputs. Additionally, the raw $\mathrm{R}_{\mathrm{sh}}$ from dark curves at the two different starting biases were not statistically different. Here it is shown that a range of values (200$800 \mathrm{ohms} \mathrm{cm}^{2}$ ) provide high PCEs (with no apparent trend for FF plotted against $\mathrm{R}_{\mathrm{sh}}$ calculated per mask area, as shown in the Supplementary Figure S2). Remarkable variation in the $\mathrm{R}_{\mathrm{sh}}$ occurs with the smallest masks, shown by an increased standard deviation (red boxes), and range between maximum and minimum values (black error bars) around the median (red circles). Figure 3B reveals a slight decrease in the median values of raw series resistance $\left(\mathrm{R}_{\mathrm{se}}\right)$, mimicking the response seen for unmasked, small active area OPV $[19,20]$. This shows a decreased effect from the ITO sheet resistance, and a trend of decreasing $\mathrm{R}_{\mathrm{se}}$ relative to decreasing mask area. The ultimate effect of masking on series resistance is shown on Figure 3C, where PCE is plotted relative to the $\mathrm{R}_{\mathrm{se}}$ for mask area (varied symbols), showing the trend of small to large $\mathrm{R}_{\mathrm{se}}$ values tied directly to the small to large mask sizes. While comparison between OPV outputs relative to $\mathrm{R}_{\mathrm{sh}}$ do not appear to have a clear trend relative to mask area (Supplementary Figure $S 2$ ), the effects of $\mathrm{R}_{\mathrm{se}}$ relative to mask area slightly increase FF and Jsc, while slightly decreasing $\mathrm{V}_{\mathrm{oc}}$. To determine at which point the mask area no longer generates these effects, we have plotted calculated PCEs from the median raw currents (black spheres, Figure 2, from all samples) relative to mask area (Figure 2, blue squares), illustrating the PCE enhancement relative to the percentage of the masked active area under illumination. From this it is apparent that the ever-smaller masks artificially enhance PCE, but there 
is a minimum size (here at $\geq 50 \%$ active area illuminated) where PCE values essentially plateau, no longer 'boosted' by the shading mask effects. This illustrates that there is a minimum mask size for samples where we can prevent the artificial boost in PCE, although it should be noted that this masking area effect may vary depending on what kind of masks or testing setup are utilized.

These trends illustrate the need to ensure that careful measurement methods are taken (including a minimum active area and sufficiently large mask) to ensure that high PCEs are accurately measured for translation to real-world OPV. Although the trend shown by our masking appears to boost device efficiency, the fact is that after examination of all data, only a minority of our highest OPV performers ( $\geq 6 \%$ PCE) were from the smallest masked area devices. Thus our device fabrication methods (when optimized), are effective at producing high efficiency devices with larger active areas, without requiring any artificial boost from these shading effects.

\subsection{Reproducibility and trend analysis}

There remain limited instances in the literature that include reproducibility analysis for their devices [26-31, 42, 43]. Considerable variation between different batches of OPV processed under near-identical conditions has been shown, resulting from small differences between processing conditions [44] or from inconsistencies in the active material's purity [45]. The 133 devices analyzed in Figure 4 were collected over the course of more than three years, produced under similar, but not always identical, conditions as reference devices for different experiments. The intent here is to determine what the average device looks like; which processing conditions actually lead to optimal results; and how to translate the best device parameters to larger active areas. Figure 4 displays data for the masked areas: $0.032 \mathrm{~cm}^{2}, 0.123 \mathrm{~cm}^{2}, 0.283 \mathrm{~cm}^{2}, 0.385 \mathrm{~cm}^{2}$, and $0.64 \mathrm{~cm}^{2}$. The median values (symbols) are compared per mask area, along with the maximum/minimum values (error bars), and the standard deviation (red boxes). These results are summarized in Table 1. For PCE calculated from the $\mathrm{J}-\mathrm{V}$ curves (Figure $4 \mathrm{~A}$ ), the median values across all devices hover at $\sim 5 \%$ (only a $7.05 \%$ variation across mask area). The comparative maximum values ranged from 5.66-6.52\%, a variation 
of only 5.14\%. The maximum PCEs reveal that the largest masked area $\left(0.64 \mathrm{~cm}^{2}\right)$ can attain a higher PCE than the smaller areas, demonstrating that a reproducible method can translate to larger areas without requiring an artificial 'boost' from small masks. There is a slight increasing trend in the smaller masks for both FF (Figure $4 \mathrm{~B}$ ) and $\mathrm{J}_{\mathrm{sc}}$ (Figure $4 \mathrm{C}$ ), with a minimal decrease in $\mathrm{V}_{\mathrm{oc}}$ (Figure 4D), as described previously. The variation between all masked values reaches a maximum of $13 \%$, revealing good reproducibility. The highest variation in standard deviation is seen for FF, confirmed by the degree of variation observed in the series and shunt resistances of Figure 3, while the $\mathrm{V}_{\mathrm{oc}}$ has the lowest variation. Analysis of variations across these device outputs can clarify where there are problems (such as FF), along with finding which fabrication parameters successfully address these issues.

For processing conditions, while both the $2: 1$ and $3: 1 \mathrm{DCB}: \mathrm{CB}$ solvent ratios used for the PCDTBT:PC ${ }_{70} \mathrm{BM}$ solution generated over $6 \%$ PCEs, the $3: 1$ ratio produced $72 \%$ of the highest PCEs, $65 \%$ of FF over $60 \%$, and $65 \%$ of $\mathrm{V}_{\mathrm{oc}}$ over $0.85 \mathrm{~V}$. Both the $2: 1$ and the $3: 1$ solvent ratios consistently outperformed the single solvent (DCB only) solution, giving more than $80 \%$ of the best performing devices. Analysis of these parameters plotted against solution ratio (Figure 5), reveals that the higher solvent ratios raise the $\mathrm{V}_{\mathrm{oc}}$ compared to the pure DCB solution, with higher maximums for FF and PCE. While active layer thickness is often a consideration across all samples, varying the active layer $(80-92 \mathrm{~nm})$ did not affect device outputs. Additionally, variation of the PEDOT-PSS annealing temperature $\left(160-200^{\circ} \mathrm{C}\right)$, did not show correlation to any specific device output. However, changing the electron transport layer thickness revealed a trend, illustrated in Figure 6A, where the median PCEs are circles and maximum and minimum values are marked by the vertical error bars. BCP thickness was varied between 4-16 nm (at set thicknesses of $4 \mathrm{~nm}, 6 \mathrm{~nm}, 8$ $\mathrm{nm}, 12 \mathrm{~nm}$, and $16 \mathrm{~nm}$, with max and min marked by the horizontal error bars). Over 6\% PCEs were obtained for thicknesses between 4-12 nm. From the median PCE values, it appears that the midrange thicknesses ( $\sim 6-8 \mathrm{~nm}$ average) is optimal, with slightly thicker films producing $56 \%$ of 
greater than $6 \%$ PCEs. The slightly thinner layers produced only $26 \%$ of the same, a trend that holds even at lower efficiency values. This relates to the PCE dependence on the device's $R_{s h}$ and $R_{s e}$ values, but still allowing considerable variation in both to produce high efficiency devices (as seen in Figure $3 B\left[R_{s h}\right]$ and $\left.3 D\left[R_{s e}\right]\right)$. Although there is some overlap in the measured BCP thicknesses (seen by the horizontal error bars of Figure 6A), shifting from the thinner layers (below $\sim 6 \mathrm{~nm}$ ) to slightly thicker layers $\left(\geq 7 \mathrm{~nm}\right.$ ) results in nearly double the median $\mathrm{R}_{\mathrm{sh}}$ value (from $\sim 200 \mathrm{ohms} \mathrm{cm}^{2}$ to $\sim 400 \mathrm{ohms} \mathrm{cm}^{2}$, Figure $6 \mathrm{~B}$ ), enhancing the overall FF and PCE. There is an unexpected slight decrease in the $\mathrm{R}_{\mathrm{se}}$ median values with increasing BCP thickness, shown in Figure 6C, since thicker films were expected to increase the series resistance. There is a minimum shunt resistance required for $\geq 6 \%$ PCE values, of $\sim 200 \mathrm{ohms} \mathrm{cm}^{2}$, although $75 \%$ of the highest PCEs had $\mathrm{R}_{\mathrm{sh}}$ between 400 $750 \mathrm{ohms} \mathrm{cm}^{2}$; consistent with reported values for similar high efficiencies [46]. There appears to be a variety of $\mathrm{R}_{\mathrm{se}}$ values that lead to high PCEs as well (although these follow a tighter grouping than $\mathrm{R}_{\mathrm{sh}}$ ), shown in Figure 3D. These range from below $1 \mathrm{ohm} \mathrm{cm}^{2}$ to $14 \mathrm{ohms} \mathrm{cm}^{2}$ for all greater-than

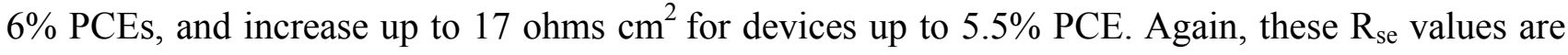
similar to those reported for high efficiency PCDTBT:PCBM devices [27, 42, 46]. In depth comparisons between different output parameters with respect to $\mathrm{R}_{\mathrm{se}}$ and $\mathrm{R}_{\mathrm{sh}}$ (Supplementary Figure S2) reveal further trends relative to mask area for series resistance, but show less mask area dependence relative to shunt resistances. For $\mathrm{R}_{\mathrm{se}}$, high FF $(\geq 60 \%)$ is achieved up to $10 \mathrm{ohms}^{2}$, with an almost linear drop off in the maximum FF compared to increasing $\mathrm{R}_{\text {se }}$ after that point. Conversely, there is a slight drop off in the maximum $\mathrm{V}_{\mathrm{oc}}$ relative to $\mathrm{R}_{\mathrm{se}}$ below $10 \mathrm{ohms} \mathrm{cm}^{2}$. There is no apparent trend between $\mathrm{J}_{\mathrm{sc}}$ and $\mathrm{R}_{\mathrm{se}}$, with high $\mathrm{J}_{\mathrm{sc}}$ achieved for all $\mathrm{R}_{\mathrm{se}}$ values. There is no clear trend relative to mask area for shunt resistance, although there is an increase in the maximum FF values with high $\mathrm{R}_{\text {sh }}$ values, and over $60 \% \mathrm{FFs}$ are achieved for $\mathrm{R}_{\text {sh }}$ between $200-800$ ohms $\mathrm{cm}^{2}$. There appears to be a slight increase in the $V_{\text {oc }}$ values as $\mathrm{R}_{\text {sh }}$ values increase; but none apparent for $\mathrm{J}_{\mathrm{sc}}$, with high values collected across all $\mathrm{R}_{\mathrm{sh}}$ values. 
Looking at the PCE values to determine the frequency of our most efficient devices, $12 \%$ of all measured devices were $6.0 \%$ PCE or higher, $25 \%$ were $\geq 5.5 \%$, and $50 \%$ of devices were $\geq 5.0 \%$. If only the best devices are chosen (above 5\% efficiency, Supplementary Figure S4), these numbers can appear higher, but do not reflect the reality of the fabrication process, where there will always be some device failure. For translation towards the marketplace, an accurate assessment of these production numbers is necessary. Comparison between the median OPV values with the maximum output (often the only number reported in the literature), there is a considerable discrepancy, with an average $22 \%$ increase of the 'hero' devices over the average device. Note that these numbers can appear higher if poor devices are removed, shown in Supplementary Table S2. The best devices (> $6 \%$ efficiency) show that the smallest areas have not produced a surfeit of the highest performers, with only $11 \%$ being the $0.032 \mathrm{~cm}^{2}$ masked area, while $44 \%$ used the largest mask $\left(0.64 \mathrm{~cm}^{2}\right)$. This trend holds true for efficiencies going down to $5 \%$, showing that effective fabrication conditions are reproducible with increasing mask areas, and can be translated to even larger device areas.

\section{Conclusions}

In order to maximize accurate measurement and reporting of OPV device efficiencies, a large sampling of best-practice $\mathrm{PCDTBT}: \mathrm{PC}_{70} \mathrm{BM}$ cells produced with slight recipe variations over the course of three years were analyzed. It was found that masking effects can artificially enhance the measured solar cell response, but using larger masks relative to the full device active area can ensure artificially high measurements are removed from the data pool. Using too-small masks enhanced the fill factor and current density, resulting from decreased series resistances, thus at least $50 \%$ of the active area should be under illumination to prevent these errors. Furthermore, analying a large data set allows the best recipe parameters to be chosen for reproducible, reliable reporting of results. There can be considerable differences between the 'hero' efficiency devices and the typical, everyday device, along with potentially low yields of the highest PCEs, often the only number reported in literature. For an accurate assessment of real-world data, across different research 
institutions, reporting the trends in average devices along with the best results is vital, and should

preferably be reported on larger active areas, especially with the trend towards proving the best-fit of novel technologies, such as the $4^{\text {th }}$ generation of OPV $[11,47-52]$.

Acknowledgements The authors gratefully acknowledge support received from the EU FP7 programme SMARTONICS and E.ON AG. M.J. Beliatis and K.D.G I. Jayawardena are also grateful for the Postdoctoral Fellowships sponsored by EPSRC and the other grant funding awarded. Dr Chris Fell (CSIRO Energy Technology) is thanked for his help on using the IVFIT software.

\section{References}

[1] S.B. Darling, F. You, The case for organic photovoltaics, RSC Adv. 3 (2013) 17633-17648.

[2] D.H. Wang, J.K. Kim, J.H. Seo, I. Park, B.H. Hong, J.H. Park, Transferable Graphene Oxide by Stamping Nanotechnology: Electron-Transport Layer for Efficient Bulk-Heterojunction Solar Cells, Angewandte Chemie International Edition. 52 (2013) 2874-2880.

[3] Y. Galagan, A. Manor, R. Andriessen, E.A. Katz, Analysis of light intensity dependence of organic photovoltaics: Towards efficient large-area solar cells, in: Photovoltaic Specialists Conference (PVSC), 2012 38th IEEE, IEEE, (2012) 002750-002752.

[4] M. Manceau, D. Angmo, M. Jørgensen, F.C. Krebs, ITO-free flexible polymer solar cells: from small model devices to roll-to-roll processed large modules, Organic Electronics. 12 (2011) 566-574.

[5] M.J. Beliatis, K.K. Gandhi, L.J. Rozanski, R. Rhodes, L. McCafferty, M.R. Alenezi, Hybrid Graphene-Metal Oxide Solution Processed Electron Transport Layers for Large Area HighPerformance Organic Photovoltaics, Advanced Materials. 26 (2014) 2078-2083.

[6] T. Miyadera, H. Ogo, T. Taima, T. Yamanari, Y. Yoshida, Analytical model for the design principle of large-area solar cells, Solar Energy Materials and Solar Cells. 97 (2012) 127131.

[7] W.-I. Jeong, J. Lee, S.-Y. Park, J.-W. Kang, J.-J. Kim, Reduction of collection efficiency of charge carriers with increasing cell size in polymer bulk heterojunction solar cells, Advanced Functional Materials. 21 (2011) 343-347.

[8] A.A.D.T. Adikaari, D.M. Dissanayake, S.R.P. Silva, Organic-inorganic solar cells: recent developments and outlook, Selected Topics in Quantum Electronics, IEEE Journal of. 16 (2010) 1595-1606.

[9] G.D.M. Dabera, K.I. Jayawardena, M.R. Prabhath, I. Yahya, Y.Y. Tan, N.A. Nismy, Hybrid carbon nanotube networks as efficient hole extraction layers for organic photovoltaics, ACS Nano. 7 (2012) 556-565.

[10] N.A. Nismy, K.D.G. Jayawardena, A.A. Adikaari, S.R.P. Silva, Photoluminescence Quenching in Carbon Nanotube-Polymer/Fullerene Films: Carbon Nanotubes as Exciton Dissociation Centres in Organic Photovoltaics, Advanced Materials. 23 (2011) 3796-3800.

[11] K.I. Jayawardena, L.J. Rozanski, C.A. Mills, M.J. Beliatis, N.A. Nismy, S.R.P. Silva, "Inorganics-in-Organics": recent developments and outlook for 4G polymer solar cells, Nanoscale. 5 (2013) 8411-8427.

[12] M. Jørgensen, J.E. Carlé, R.R. Søndergaard, M. Lauritzen, N.A. Dagnla es-Hansen, S.L. Byskov, The state of organic solar cells-A meta analysis, Solar Energy Materials and Solar Cells. 119 (2013) 84-93. 
[13] H.-C. Liao, C.-C. Ho, C.-Y. Chang, M.-H. Jao, S.B. Darling, W.-F. Su, Additives for morphology control in high-efficiency organic solar cells, Materials Today. 16 (2013) 326 -336 .

[14] S.A. Gevorgyan, J. Eggert Carlé, R. Søndergaard, T. Trofod Larsen-Olsen, M. Jørgensen, F.C. Krebs, Accurate characterization of OPVs: Device masking and different solar simulators, Solar Energy Materials and Solar Cells. 110 (2013) 24-35.

[15] V. Shrotriya, G. Li, Y. Yao, T. Moriarty, K. Emery, Y. Yang, Accurate measurement an characterization of organic solar cells, Advanced Functional Materials. 16 (2006) 20162023.

[16] H.J. Snaith, How should you measure your excitonic solar cells?, Energy \& Environmental Science. 5 (2012) 6513-6520.

[17] H.J. Snaith, The perils of solar cell efficiency measurements, Nature Photonics. 6 (2012) 337-340.

[18] J.D. Servaites, M.A. Ratner, T.J. Marks, Organic solar cells: a new look at traditional models, Energy \& Environmental Science. 4 (2011) 4410-4422.

[19] D. Gupta, M. Bag, K.S. Narayan, Area dependent efficiency of organic solar cells, Applied Physics Letters. 93 (2008) 163301.

[20] S. Choi, W.J. Potscavage Jr, B. Kippelen, Area-scaling of organic solar cells, Journal of Applied Physics. 106 (2009) 054507.

[21] T. Winkler, H. Schmidt, H. Flügge, F. Nikolayzik, I. Baumann, S. Schmale, Efficient large area semitransparent organic solar cells based on highly transparent and conductive ZTO/Ag/ZTO multilayer top electrodes, Organic Electronics. 12 (2011) 1612-1618.

[22] M.W. Denhoff, N. Drolet, The effect of the front contact sheet resistance on solar cell performance, Solar Energy Materials and Solar Cells. 93 (2009) 1499-1506.

[23] S.-Y. Park, W.-I. Jeong, D.-G. Kim, J.-K. Kim, D.C. Lim, J.H. Kim, Large-area organic solar cells with metal subelectrode on indium tin oxide anode, Applied Physics Letters. 96 (2010) 173301.

[24] M.-S. Kim, M.-G. Kang, L.J. Guo, J. Kim, Choice of electrode geometry for accurate measurement of organic photovoltaic cell performance, Applied Physics Letters. 92 (2008) 133301 .

[25] A. Cravino, P. Schilinsky, C.J. Brabec, Characterization of organic solar cells: the importance of device layout, Advanced Functional Materials. 17 (2007) 3906-3910.

[26] J.H. Seo, A. Gutacker, Y. Sun, H. Wu, F. Huang, Y. Cao, Improved high-efficiency organic solar cells via incorporation of a conjugated polyelectrolyte interlayer, Journal of the American Chemical Society. 133 (2011) 8416-8419.

[27] H. Jin, C. Tao, M. Velusamy, M. Aljada, Y. Zhang, M. Hambsch, Efficient, large area 
ITO-and-PEDOT-free organic solar cell sub-modules, Advanced Materials. 24 (2012) 2572-2577.

[28] S. Kannappan, K. Palanisamy, J. Tatsugi, P.-K. Shin, S. Ochiai, Fabrication and characterizations of PCDTBT: PC71BM bulk heterojunction solar cell using air brush coating method, Journal of Materials Science. 48 (2013) 2308-2317.

[29] Y. Zhao, L. Chen, C. Li, K. Müllen, Effects of a bathophenanthroline exciton blocking layer on thermal annealing-free bulk heterojunction solar cells, Synthetic Metals. 174 (2013) 46-49.

[30] E.L. Ratcliff, J. Meyer, K.X. Steirer, N.R. Armstrong, D. Olson, A. Kahn, Energy level alignment in PCDTBT: $\mathrm{PC}_{70} \mathrm{BM}$ solar cells: Solution processed $\mathrm{NiO}_{\mathrm{x}}$ for improved hole collection and efficiency, Organic Electronics. 13 (2012) 744-749.

[31] E.S. Bovill, J. Griffin, T. Wang, J.W. Kingsley, H. Yi, A. Iraqi, Air processed organic photovoltaic devices incorporating a MoOx anode buffer layer, Applied Physics Letters. 102 (2013) 183303.

[32] T.T. Larsen-Olsen, S.A. Gevorgyan, R.R. Søndergaard, M. Hösel, Z. Gu, H. Chen, A round robin study of polymer solar cells and small modules across China, Solar Energy Materials and Solar Cells. 117 (2013) 382-389.

[33] S. Alem, T.-Y. Chu, S.C. Tse, S. Wakim, J. Lu, R. Movileanu, Effect of mixed solvents on PCDTBT: PC $_{70}$ BM based solar cells, Organic Electronics. 12 (2011) 1788-1793.

[34] V.S. Gevaerts, A. Furlan, M.M. Wienk, M. Turbiez, R.A. Janssen, Solution processed polymer tandem solar cell using efficient small and wide bandgap polymer: fullerene blends, Advanced Materials. 24 (2012) 2130-2134.

[35] C.-F. Lin, B.-H. Lin, S.-W. Liu, W.-F. Hsu, M. Zhang, T.-L. Chiu, Optical effects of shadow masks on short circuit current of organic photovoltaic devices, Physical Chemistry Chemical Physics. 14 (2012) 3837-3842.

[36] E.A. Katz, J.M. Gordon, W. Tassew, D. Feuermann, Photovoltaic characterization of concentrator solar cells by localized irradiation, Journal of Applied Physics. 100 (2006) 044514.

[37] I. Riedel, N. Martin, F. Giacalone, J.L. Segura, D. Chirvase, J. Parisi, Polymer solar cells with novel fullerene-based acceptor, Thin Solid Films. 451 (2004) 43-47.

[38] J. Rostalski, D. Meissner, Photocurrent spectroscopy for the investigation of charge carrier generation and transport mechanisms in organic p/n-junction solar cells, Solar Energy Materials and Solar Cells. 63 (2000) 37-47.

[39] D. Gao, D.S. Seferos, Size-dependent behavior of polymer solar cells measured under partial illumination, Solar Energy Materials and Solar Cells. 95 (2011) 3516-3519.

[40] R. Steim, T. Ameri, P. Schilinsky, C. Waldauf, G. Dennler, M. Scharber, Organic photovoltaics for low light applications, Solar Energy Materials and Solar Cells. 95 (2011) 
$3256-3261$.

[41] A.R. Burgers, J.A. Eikelboom, A. Schonecker, W.C. Sinke, Improved treatment of the strongly varying slope in fitting solar cell IV curves, in: Photovoltaic Specialists Conference, 1996., Conference Record of the Twenty Fifth IEEE, IEEE, 1996: pp. 569572.

[42] J.S. Moon, J. Jo, A.J. Heeger, Nanomorphology of PCDTBT: PC70BM bulk heterojunction solar cells, Advanced Energy Materials. 2 (2012) 304-308.

[43] Z. He, C. Zhong, X. Huang, W.-Y. Wong, H. Wu, L. Chen, Simultaneous enhancement of open-circuit voltage, short-circuit current density, and fill factor in polymer solar cells, Advanced Materials. 23 (2011) 4636-4643.

[44] M.K. Riede, K.O. Sylvester-Hvid, M. Glatthaar, N. Keegan, T. Ziegler, B. Zimmermann, High throughput testing platform for organic solar cells, Progress in Photovoltaics: Research and Applications. 16 (2008) 561-576.

[45] M.P. Nikiforov, B. Lai, W. Chen, S. Chen, R.D. Schaller, J. Strzalka, Detection and role of trace impurities in high-performance organic solar cells, Energy \& Environmental Science. 6 (2013) 1513-1520.

[46] Y. Zhu, X. Xu, L. Zhang, J. Chen, Y. Cao, High efficiency inverted polymeric bulkheterojunction solar cells with hydrophilic conjugated polymers as cathode interlayer on ITO, Solar Energy Materials and Solar Cells. 97 (2012) 83-88.

[47] R.A. Hatton, N.P. Blanchard, L.W. Tan, G. Latini, F. Cacialli, S.R.P. Silva, Oxidised carbon nanotubes as solution processable, high work function hole-extraction layers for organic solar cells, Organic Electronics. 10 (2009) 388-395.

[48] R.A. Hatton, N.P. Blanchard, V. Stolojan, A.J. Miller, S.R.P. Silva, Nanostructured copper phthalocyanine-sensitized multiwall carbon nanotube films, Langmuir. 23 (2007) 64246430.

[49] R.A. Hatton, A.J. Miller, S.R.P. Silva, Carbon nanotubes: a multi-functional material for organic optoelectronics, Journal of Materials Chemistry. 18 (2008) 1183-1192.

[50] A.J. Miller, R.A. Hatton, G.Y. Chen, S.R.P. Silva, Carbon nanotubes grown on In2O3: Sn glass as large area electrodes for organic photovoltaics, Applied Physics Letters. 90 (2007) 023105 .

[51] A.J. Miller, R.A. Hatton, S.R.P. Silva, Interpenetrating multiwall carbon nanotube electrodes for organic solar cells, Applied Physics Letters. 89 (2006) 133117.

[52] A.J. Miller, R.A. Hatton, S.R.P. Silva, Water-soluble multiwall-carbon-nanotubepolythiophene composite for bilayer photovoltaics, Applied Physics Letters. 89 (2006) 123115. 


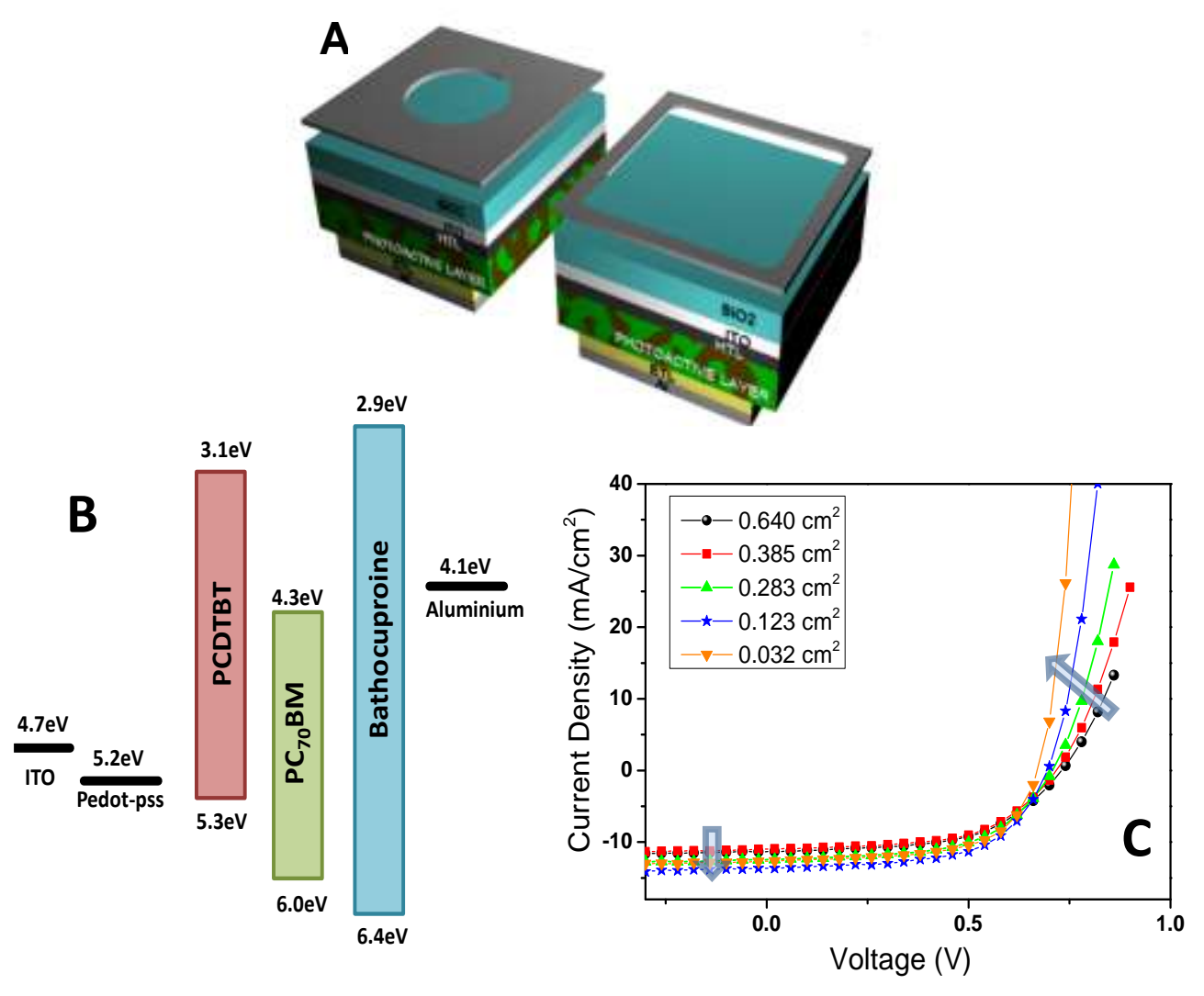

Figure 1. (A) Depiction of OPV architecture, with illustration of masks with different types of apertures. (B) Energy level diagram of the materials used in the OPV. (C) J-V curves showing the enhanced fill factor and increasing $\mathrm{J}_{\mathrm{sc}}$ relative to mask area.

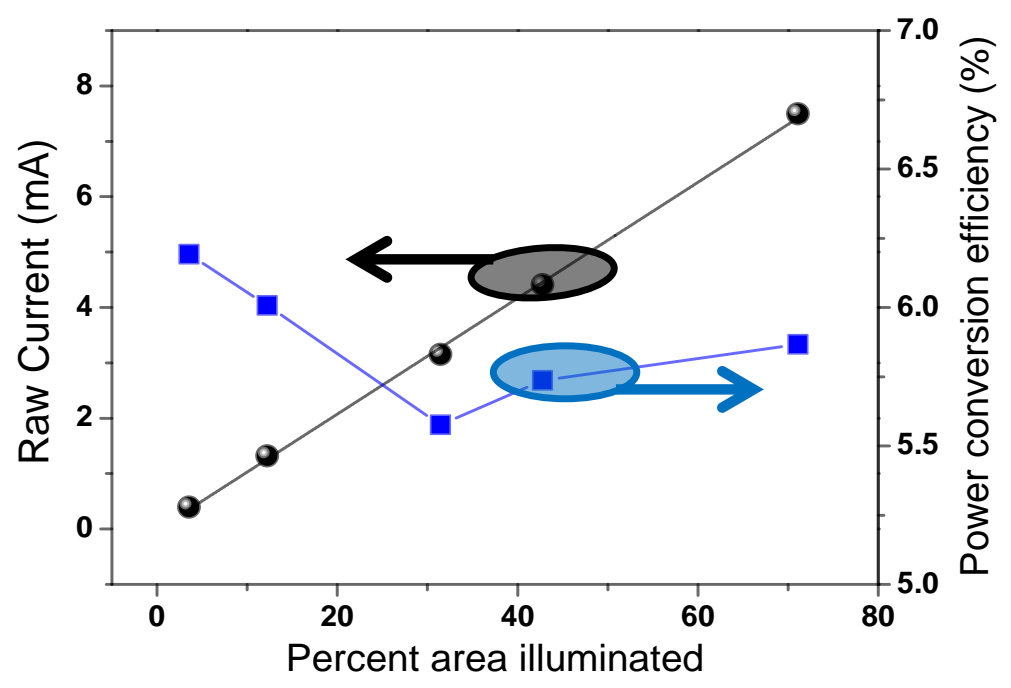

Figure 2. Median raw current plotted as a function of active area under illumination (black circles) and resultant PCEs calculated using these values (blue squares). 

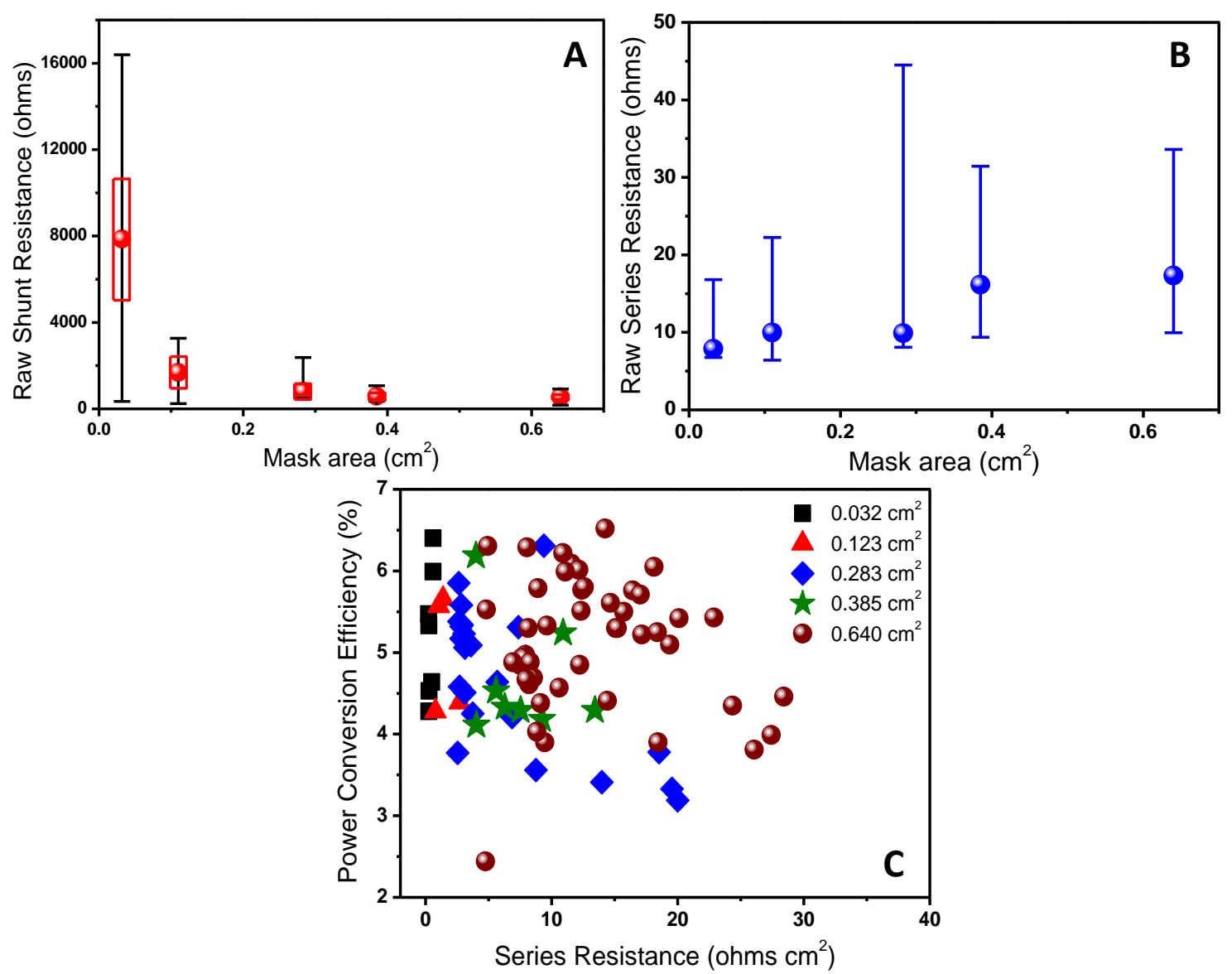

Figure 3. (A) Raw shunt resistances plotted against mask area, the median (red circles) raw shunt resistances, with $\max /$ min values (black error bars) and standard deviation (red boxes), showing the increase with the smallest masks. (B) Raw series resistances plotted against mask area, (blue circles) raw shunt resistances, with $\max /$ min values (blue error bars), showing a slight decrease relative to mask area. (C) PCE measured for mask area used, plotted against series resistances. 

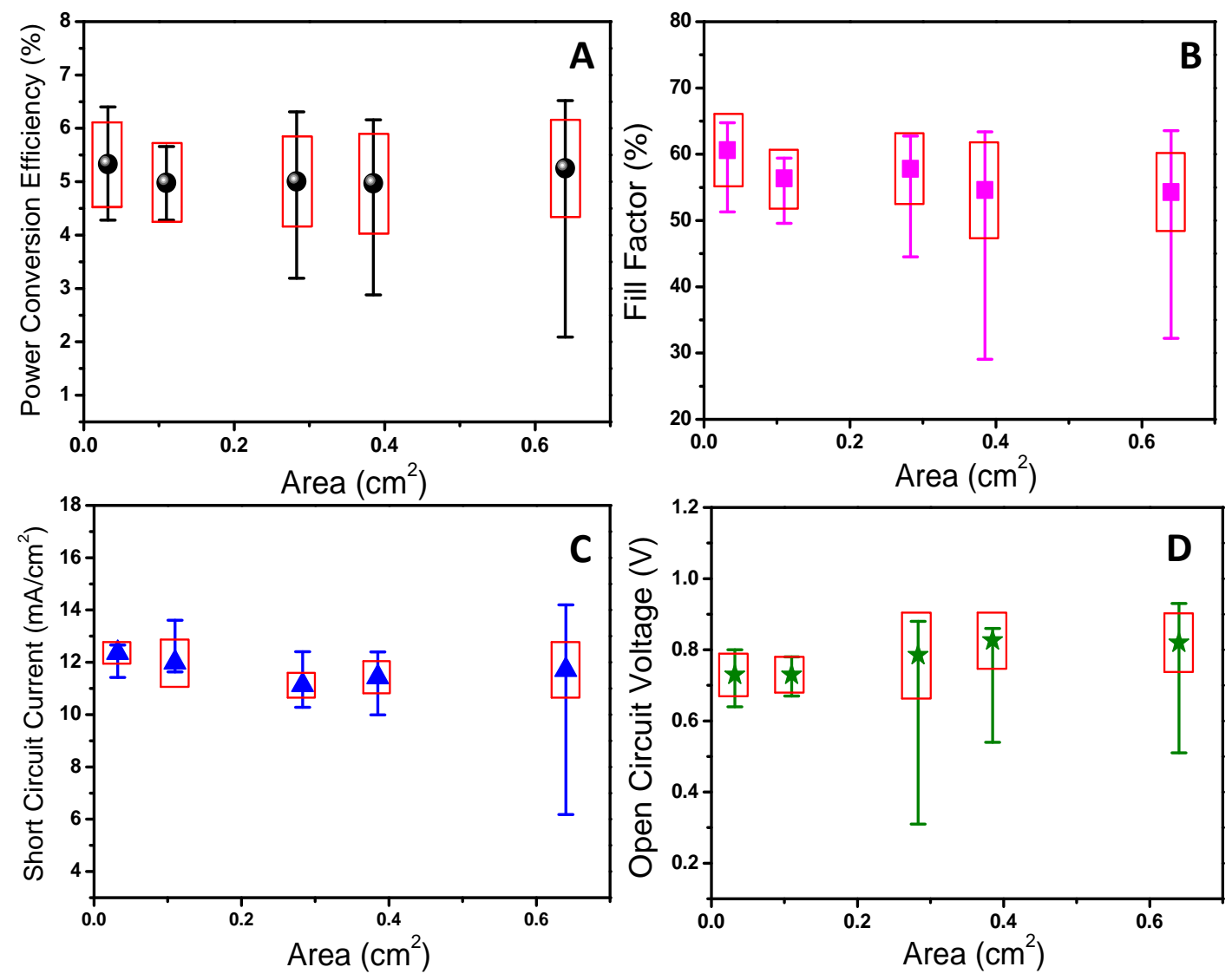

Figure 4. OPV device trends showing the median value per mask area (symbols), the maximum and minimum values (error bars), and the standard deviation (boxed areas) for PCE (A), FF (B), $\mathrm{J}_{\mathrm{sc}}(\mathrm{C})$ and $\mathrm{V}_{\mathrm{oc}}(\mathrm{D})$.

Table 1. Summary of trends across all masked and unmasked devices, with standard deviation shown in parenthesis.

\begin{tabular}{|c|c|c|c|c|c|}
\hline $\begin{array}{c}\text { Device area } \\
\left(\mathrm{cm}^{2}\right)\end{array}$ & Efficiency \% & $\begin{array}{c}\text { Max } \\
\text { Efficiency \% }\end{array}$ & $\begin{array}{c}\text { Open Circuit } \\
\text { Voltage (V) }\end{array}$ & $\begin{array}{c}\text { Fill Factor } \\
(\%)\end{array}$ & $\begin{array}{c}\text { Short Circuit } \\
\text { Current }\left(\mathrm{mA} / \mathrm{cm}^{2}\right)\end{array}$ \\
\hline 0.032 & $5.33( \pm 0.79)$ & 6.40 & $0.73( \pm 0.06)$ & $60.6( \pm 5.44)$ & $12.4( \pm 0.42)$ \\
\hline 0.110 & $4.98( \pm 0.74)$ & 5.66 & $0.73( \pm 0.05)$ & $56.4( \pm 4.46)$ & $12.0( \pm 0.91)$ \\
\hline 0.283 & $5.01( \pm 0.85)$ & 6.31 & $0.79( \pm 0.12)$ & $57.8( \pm 5.63)$ & $11.1( \pm 0.47)$ \\
\hline 0.385 & $4.97( \pm 0.93)$ & 6.20 & $0.83( \pm 0.08)$ & $54.6( \pm 7.22)$ & $11.4( \pm 0.62)$ \\
\hline 0.640 & $5.25( \pm 0.91)$ & 6.52 & $0.82( \pm 0.08)$ & $54.3( \pm 5.89)$ & $11.7( \pm 1.07)$ \\
\hline
\end{tabular}



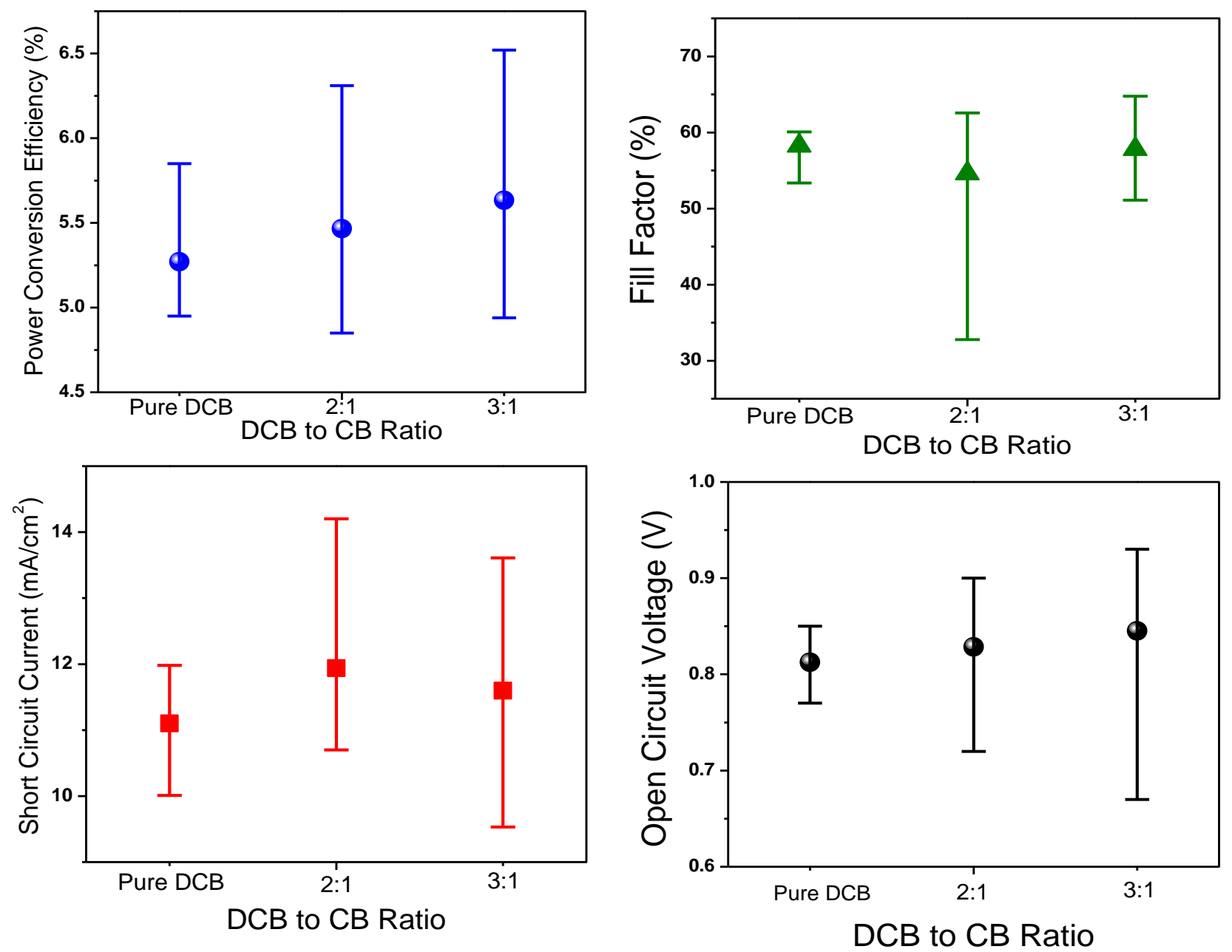

Figure 5: OPV results plotted against the solvent ratio used for the identical mass/ratio of PCDTBT:PC ${ }_{70} \mathrm{BM}$ solutions, ranging from pure Dichlorobenzene (DCB), to a 2:1 DCB to Chlorobenzene (CB) ratio, and 3:1 $\mathrm{DCB}$ to $\mathrm{CB}$ ratio. 

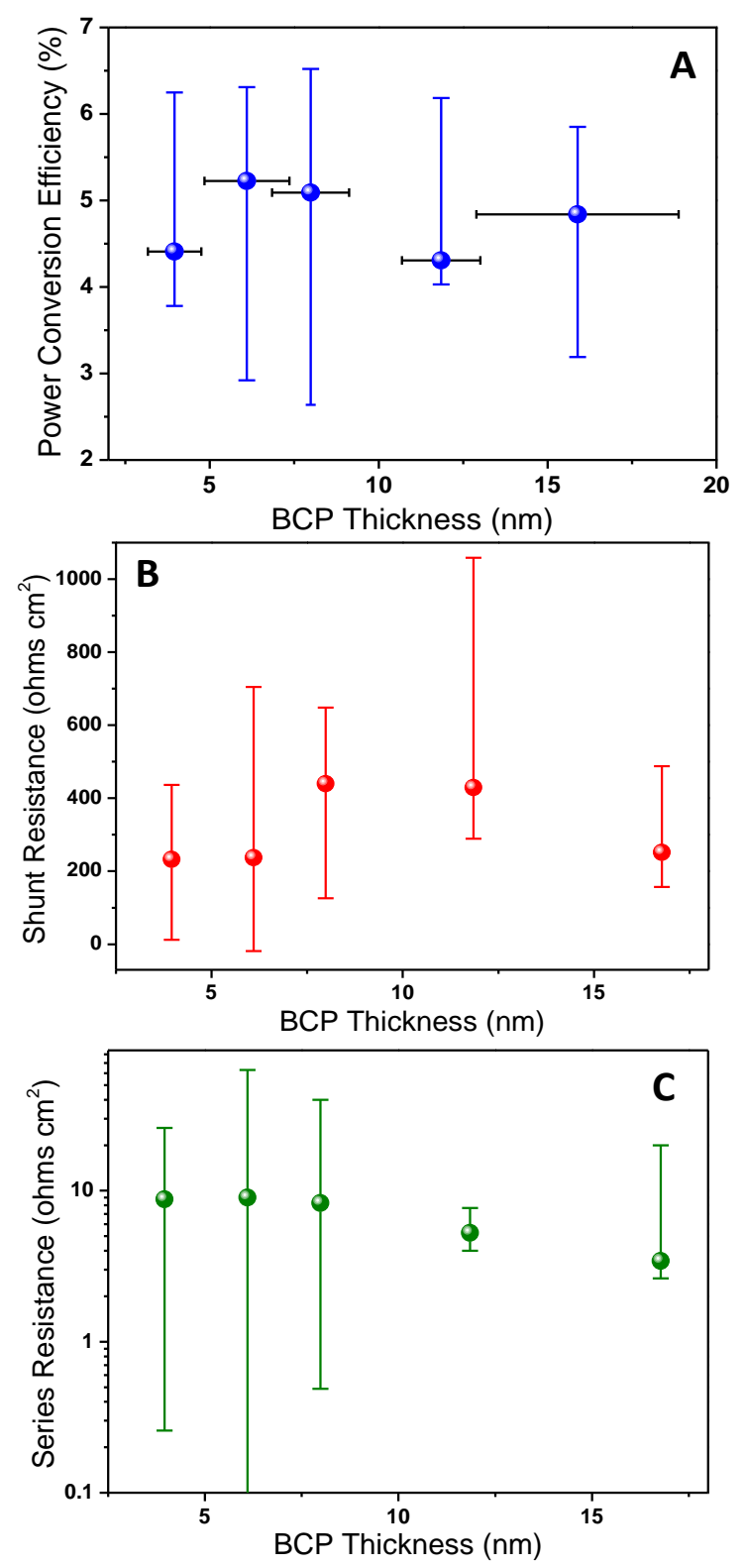

Figure 6. (A) Power Conversion Efficiency relative to thickness of the BCP electron transport layer, (B) Shunt resistance relative to BCP thickness, and (C) Series resistance relative to BCP thickness (log-linear scale). For all graphs, the median values are the spheres, with max and min values marked by the error bars. 